\title{
Development of standards for flash thermography and lock-in thermography
}

\author{
by Ch. Maierhofer*, P. Myrach*, H. Steinfurth*, M. Reischel*, and M. Röllig* \\ * BAM Federal Institute for Materials Research and Testing, Division 8.4, Unter den Eichen 87, 12205 Berlin, \\ Germany, christiane.maierhofer@bam.de
}

\begin{abstract}
Standards for the application of flash thermography as well as of lock-in thermography are urgently required. Both methods are applied more and more often in research and industry, but still extensive validation procedures are required for each individual application. In this paper, the results of two research projects concerning the validation and standardisation of both methods are presented. This includes results of a detailed study of the influence of measurements parameters on flash thermography, of the comparison of the lateral resolution obtained with flash and lock-in thermography and the description of a draft standard for flash thermography.
\end{abstract}

\section{Introduction}

The area of application of active thermography methods like flash and lock-in thermography for non-destructive testing is increasing rapidly and is expanding for testing of safety relevant structures and components in aerospace, automotive and energy industries. Thus, a standardization of equipment, data acquisition processes and data analysis and interpretation is needed for securing reliable and reproducible testing results. Currently, there are existing only national standards like DIN 54190-1 to 3 describing general principle, equipment and terms and definitions for thermography in non-destructive testing, DIN 54191 for thermographic testing of electrical equipment and since 2010 the first standard on active thermography, DIN 54192. Most parts of these standards have been passed to CEN/TC138/WG11 Infrared Thermographic Testing. Recently, the first European standard prEN 16714-1 concerning general principles is under enquiry, further European standards are drafted. ASTM E 2582-07 Standard Practice for Infrared Flash Thermography of Composite Panels and Repair Patches Used in Aerospace Applications is the first standard describing the procedure for a concrete application of flash thermography using thermal signal reconstruction (TSR) for data analysis. The application of periodic heating is standardizes in EN 15042-2 for the thickness measurement of coatings. But here, only single detectors and no imaging systems like infrared (IR) cameras are considered.

For active thermography, standards are still missing which describe the areas of application, the selection of excitation sources and parameters adapted to each testing problem, the combination of excitation methods, measurement uncertainties and how these are influenced by material as well as by measurements parameters, limits of the methods etc. Further on, there are no specifications for reference test specimen and calibration standards, which might be used for controlling specifications of equipment and method.

Up to now it is not clear for which materials and testing problems flash thermography should be preferred against lock-in thermography, although costs for excitation sources and time for data recording are quite different for both methods. Flash thermography is based on short pulsed optical excitation of the objects under investigation. Typically, a flash lamp with pulse duration between 1 and $10 \mathrm{~ms}$ is used. For reaching high excitation energies and thus large penetration depths as well as for testing larger areas, up to eight lamps [1] or even more can be applied, although costs for equipment purchase and maintenance are relatively high. Flash excitation might be optimized by adjustable pulse length, which can be achieved by flash quenching [2] and by reducing disturbances of data recording through direct infrared radiation during and after excitation (afterglow) using infrared filters. Further developments are concerning optimized data analysis like early time detection [3]. Systematic comparisons of flash thermography to conventional NDT techniques like ultrasonics and computed tomography show that similar or even more detailed quantitative information is gained by the thermal method with the advantage of less time and effort required for testing [4, 5]. Data recording is performed during and after pulse excitation, while data analysis is only applied to the data recorded during cooling down. Data processing is performed in different ways: visualization of thermal contrast, pulse phase thermography using Fast Fourier Transformation (FFT), Thermal Signal Reconstruction (TSR) and further algorithms [3]. As shown below, measurement parameters like camera specification and parameters (wavelength, lens, integration time), excitation sources (number of flash lamps, infrared filters in front of the lamps), experimental set-up as well as the methods for data analysis have to be optimized for obtaining maximum signal-to-noise ratio (SNR) and thus optimum detectability of defects.

With lock-in thermography, the object under investigation is heated periodically while the surface temperature is recorded simultaneously with the IR camera. Already while measuring (on-line lock-in) or after the measurement (off-line lock-in), the recorded thermal response is correlated with the excitation signal to obtain amplitude and phase images. Within the model of thermal waves, thermal waves generated at the surface and thermal waves reflected at internal thermal discontinuities are superimposing. Thus, the phase angle recorded at the surface depends on coverage, reflection coefficient of discontinuities as well as on material parameters [6]. As a consequence, the detectability of 
defects is strongly correlated with excitation frequency, but also depends on camera specifications and parameters, excitation sources and data processing [7]. Recent developments in optical lock-in thermography are concerning the usage of LED-arrays emitting at wavelengths where the IR camera is not sensitive [8] or of excitation by spatially adapted energy distribution generated by digital light projectors (DLPs) in order to reduce lateral temperature gradients and thus preventing lateral heat conduction [9]. In contrast to flash thermography, the equipment needed for periodic optical heating using halogen lamps is less expensive. But depending on excitation frequency and the number of recorded periods, in general much longer time is needed for data acquisition.

Up to now, there have been published only a few studies concerning the comparison of flash and lock-inthermography $[4,10,11]$. These studies are analyzing the penetration depth as well as the SNR concerning mainly artificial defects. A comparison of depth or lateral resolution was not given. Especially for deeper defects in metal structures, these studies found that lock-in thermography leads to defect detection with higher SNR. But in most cases, no clear advantage of one of these methods could be evaluated. Therefore, in the study presented below, the comparison of flash thermography and lock-in thermography for standardization is for the first time also focusing on the lateral resolution.

\section{Influence of measurement parameters on flash thermography}

\subsection{Experimentals}

For the investigation of the influence of measurement parameters on flash thermography, a steel sample with a size of $150 \times 150 \times 25 \mathrm{~mm}^{3}$ with flat bottom holes having a diameter of $12 \mathrm{~mm}$ and remaining wall thicknesses of 2, 4, 6, and $8 \mathrm{~mm}$ has been investigated using four flash lamps with $6 \mathrm{~kJ}$ each and a cooled InSb infrared camera with a SMWIR lens, see figure 1 a) ( here a set-up of two flash lamps and an additional copper test specimen is shown). The surface of the test specimens was blackened. As measurement parameters, the integration time (0.1 to $1.2 \mathrm{~ms}$ ), band pass filters in front of the detector, Plexiglas filters in front of the flash lamps and the number of flash lamps ( 2 and 4$)$ have been varied. The maximum frame rate of the camera was $93 \mathrm{~Hz}$ with a frame size of $640 \times 512$ pixels.

\subsection{Results}

In figure $1 \mathrm{~b}$ ) and c), two thermograms recorded $0.5 \mathrm{~s}$ and $3.2 \mathrm{~s}$ after the flash at the surface of the steel test specimen are shown. Here, for each image ten sequenced thermograms have been averaged and the intensity of the first thermogram before heating was subtracted. In figure $1 \mathrm{~b}$ ), the optimum contrast for the shallowest hole is shown while figure $1 \mathrm{c}$ ) was selected to demonstrate that all holes could be detected, thus the penetration depth was about $8 \mathrm{~mm}$ at least.

In the diagrams in fig. 2, the thermal contrasts of the shallowest flat bottom hole with a remaining wall thickness of $2 \mathrm{~mm}$ are shown for the different measurement parameters. Doubling the integration time leads to a doubling of intensity, but also to an increase of noise (figure 2 a)). Thus, the increase of SNR is less than a factor of two. Reducing the band width of the infrared camera from 1.6-5.4 $\mu \mathrm{m}$ to 3.7-5.4 $\mu \mathrm{m}$ leads only to a slight decrease of intensity, while a clear reduction of about $60 \%$ is obtained with a reduced band width of 4.4-5.4 $\mu \mathrm{m}$ (figure $2 \mathrm{~b}$ )). Losses due to absorption as well as due to reflection lead to a nonlinear decrease of intensity contrast with increasing number of Plexiglas sheets (figure $2 \mathrm{c})$ ). The cooling down of the samples is only slightly influenced by the Plexiglas sheets. As expected, the intensity contrast increases by a factor of two if four instead of only two flash lamps are used synchronously (figure $2 \mathrm{~d}$ )). The results of these investigations are summarized in table 1.

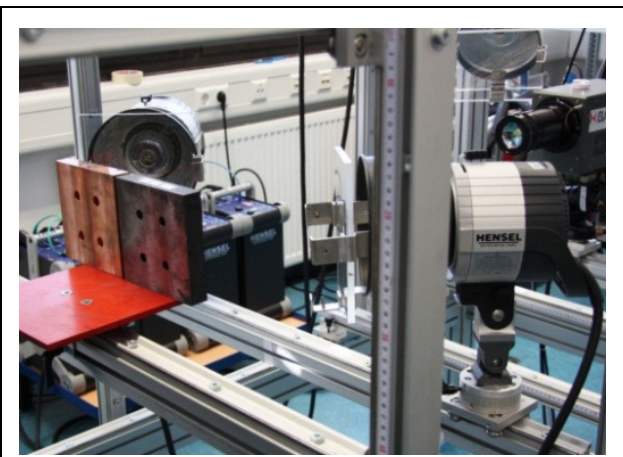

a)

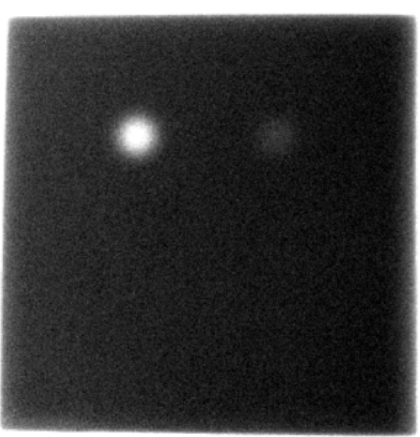

b) 97-184 digits from black to white

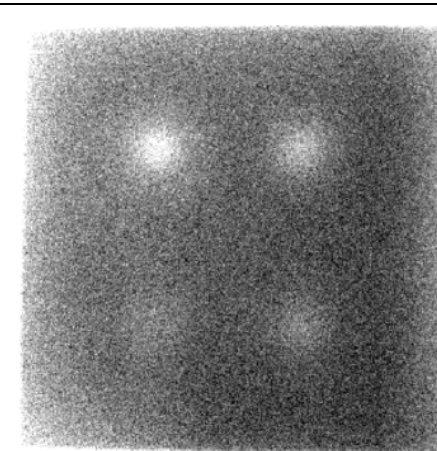

c) 41-71 digits from black to white

Fig. 1. Experimental set-up for flash thermography using two flash lamps (a) and thermograms of the steel sample with four flat bottom holes after $0.5 \mathrm{~s}(\mathrm{~b})$ and after $3.2 \mathrm{~s}(\mathrm{c})$. 


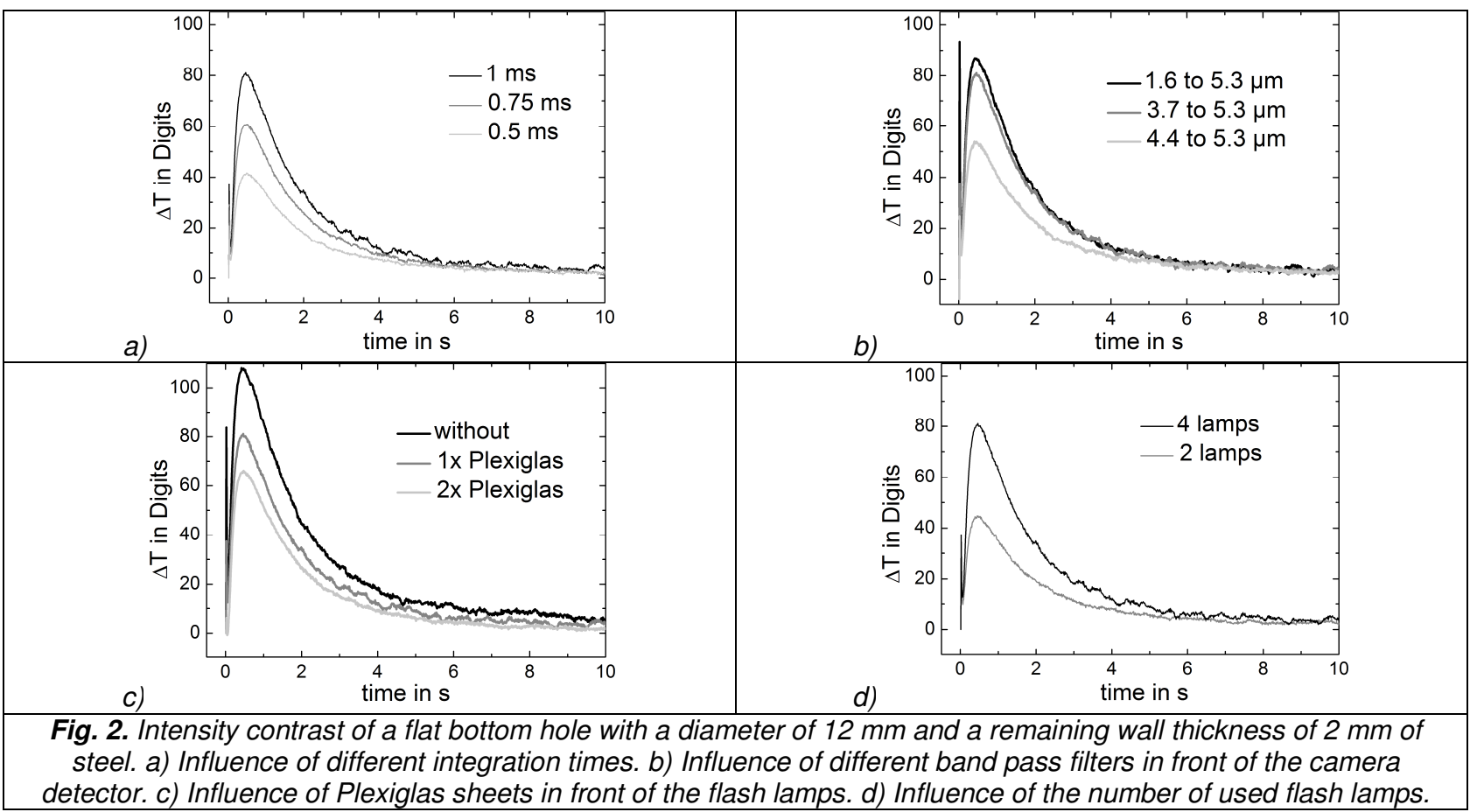

Table 1. Influence of measurement parameter on intensity contrast for flash thermography

\begin{tabular}{|c|c|}
\hline Measurement parameter & Influence on intensity contrast \\
\hline Integration time & $\begin{array}{l}\text { Intensity contrast increases linearly with integration time, but at the same time the noise } \\
\text { increases. The SNR is proportional to the square root of the integration time. }\end{array}$ \\
\hline $\begin{array}{l}\text { Filter in front of the } \\
\text { detector of the IR } \\
\text { camera }\end{array}$ & $\begin{array}{l}\text { Essential intensity losses are occurring by changing the filters from a bandwidth of } 3.7 \text { to } \\
5.3 \mu \mathrm{m} \text { to a bandwidth of } 4.4 \text { to } 5.3 \mu \mathrm{m} \text {. Thus the radiation in the range from } 3.7 \text { to } 4.4 \mu \mathrm{m} \\
\text { has a reasonable contribution to the signal intensity. }\end{array}$ \\
\hline $\begin{array}{l}\text { Plexiglas plates in front } \\
\text { of the flash lamps }\end{array}$ & $\begin{array}{l}\text { With increasing overall thickness of the Plexiglas sheets the intensity contrast decreases. } \\
\text { On the observed cooling down behaviour, the Plexiglas sheets have only a slight } \\
\text { influence. }\end{array}$ \\
\hline Number of flash lamps & A doubling of excitation energy leads to a doubling of intensity contrast and of SNR. \\
\hline
\end{tabular}

\section{Comparison of spatial resolution of flash and lock-in thermography}

\subsection{Experimentals}

For the comparison of spatial resolution of flash and lock-in thermography in metal structures, a steel sample with crossed notches with remaining wall thicknesses of 2 and $3 \mathrm{~mm}$ and with a wedge (not discussed here) has been investigated (see figure 3 a)). Also here, the surface was blackened before the measurements. The lock-in measurements have been performed using a cooled InSb IR camera with a MWIR lens and two halogen lamps with a maximum power of $500 \mathrm{~W}$ each. The excitation frequencies have been varied from 1 to $0.05 \mathrm{~Hz}$. Measurement time and frame rate have been adjusted so that for each frequency, at least 20 periods have been recorded. For flash thermography, the same IR camera with four flashes and Plexiglas sheets in front of the flash lamps have been used. Here, the cooling down has been recorded with a frame rate of $200 \mathrm{~Hz}$ for a duration of $20 \mathrm{~s}$.

For the investigation of the influence of measurement methods on the spatial resolution in CFRP samples, a CFRP plate was used consisting of 32 biaxial carbon fibre fabric layers $\left(+/-45^{\circ}\right)$, which have been oriented quasiisotropic and symmetrically to the middle axis $(9 x+45 /-45 / 0 / 90$ and $9 \times 90 / 0 /+45 /-45)$, and of epoxy resin. The thickness of the sample was about $6 \mathrm{~mm}$. Several flat bottom holes have been drilled with diameters of 4, 8, 16 and $32 \mathrm{~mm}$ and different remaining wall thicknesses (see figure $3 \mathrm{~b}$ )). For the measurements, no blackening of the sample was required. For lockin as well as for flash measurements, the same equipment as described above was used. For lock-in thermography, excitation frequencies from 0.25 to $0.01 \mathrm{~Hz}$ have been applied. The measurements with flash thermography have been recorded for a duration of about $100 \mathrm{~s}$. 




\subsection{Results}

\subsubsection{Steel test specimen with crossed notches}

The phase images of the steel test specimen shown in figure 4 have been calculated using FFT (standard function of Matlab) from the data recorded with lock-in excitation (top) and flash excitation (bottom). The small black sprinkles on the surface are resulting from small defects in the blackening layers of the samples. After lock-in excitation and before flash excitation, this layers was renewed, but again inhomogeneities appeared, but at different positions.

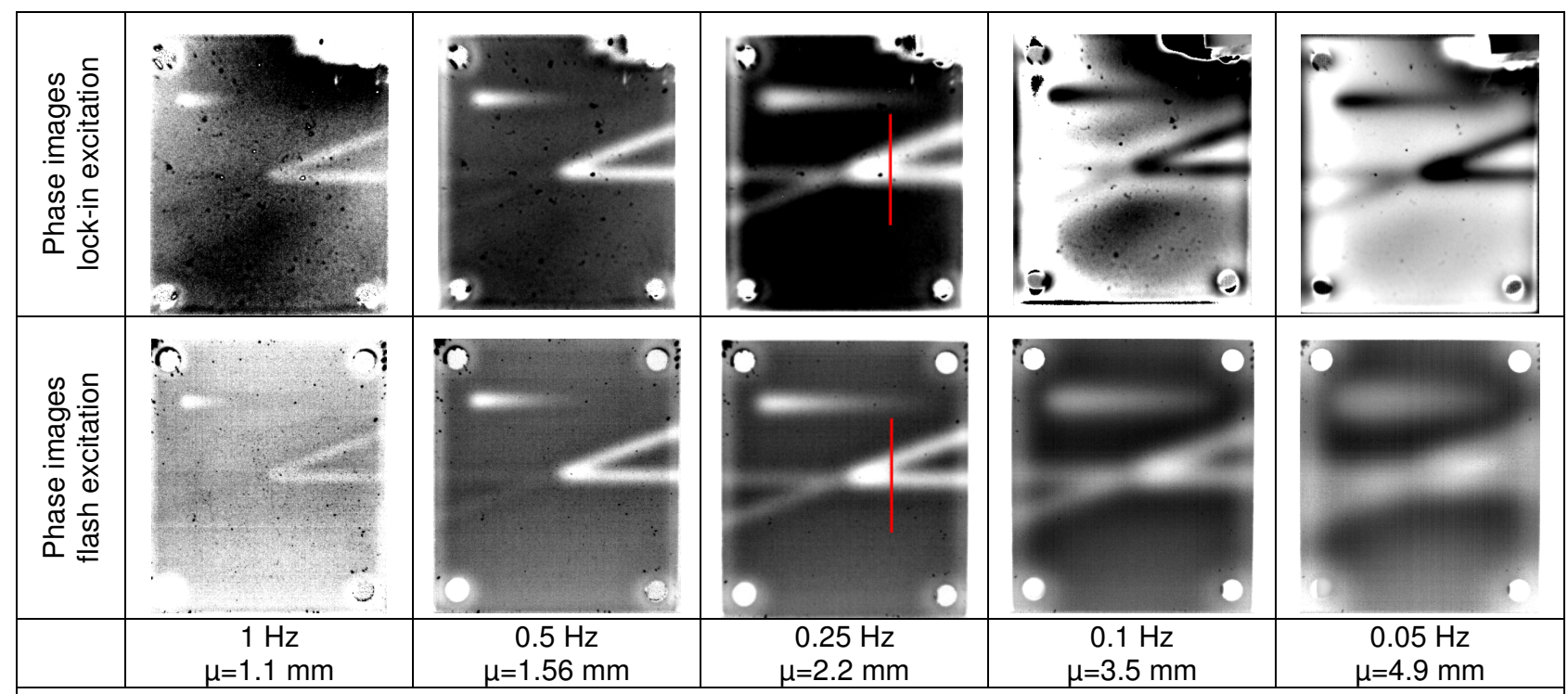

Fig. 4: Phase images of crossed notches with remaining wall thicknesses of $3 \mathrm{~mm}$ on the left and $2 \mathrm{~mm}$ on the right recorded at different frequencies. The images have been optimized to the $2 \mathrm{~mm}$ notches. Top: Phase images of lockin measurements at different frequencies. Bottom. Phase images of flash thermography. The red line marks the position of the line scans. 
By using the known relationship between diffusion length $\mu$ and thermal diffusivity $\alpha\left(\mu=\sqrt{\frac{2 \alpha}{\omega}}\right)$, the diffusion length was calculated for each excitation frequency and is also shown in figure 4. From a first view of the phase images, it becomes evident that the spatial resolution of lock-in and flash thermography is similar or even better for flash excitation for frequencies from $1 \mathrm{~Hz}$ to $0.25 \mathrm{~Hz}$. For lower frequency, the resolution of the phase images calculated from flash excitation becomes remarkably worse in comparison to lock-in excitation. For the latter one, a phase wrap can be observed for frequencies lower than $0.25 \mathrm{~Hz}$.

For a better analysis of spatial resolution, line scans have been extracted for each phase image perpendicular to the crossed notches with a remaining thickness of $2 \mathrm{~mm}$, not far from the cross (see red line in figure 4). These line scans, which are an average of three neighbouring lines, are shown in figure 5 for lock-in excitation (figure 5 a)) as well as for flash excitation (figure $5 \mathrm{~b}$ )). Here it becomes clearer that from $1 \mathrm{~Hz}$ down to $0.25 \mathrm{~Hz}$, the spatial resolution quantified by the depth of the valley between the two single notches is better for flash excitation than for lock-in excitation, while the phase contrast and also the SNR seems to be higher for lock-in excitation. For lower frequencies, the lateral resolution of the lock-in line scans is much better. For the lock-in scans, it can be observed that first with decreasing frequency, the lateral resolution is decreasing up to $0.25 \mathrm{~Hz}$, while with further decreasing frequency, the lateral resolution increases and becomes much better than before. Actually for lock-in excitation, the lateral resolution becomes best for an excitation frequency of $0.1 \mathrm{~Hz}$.
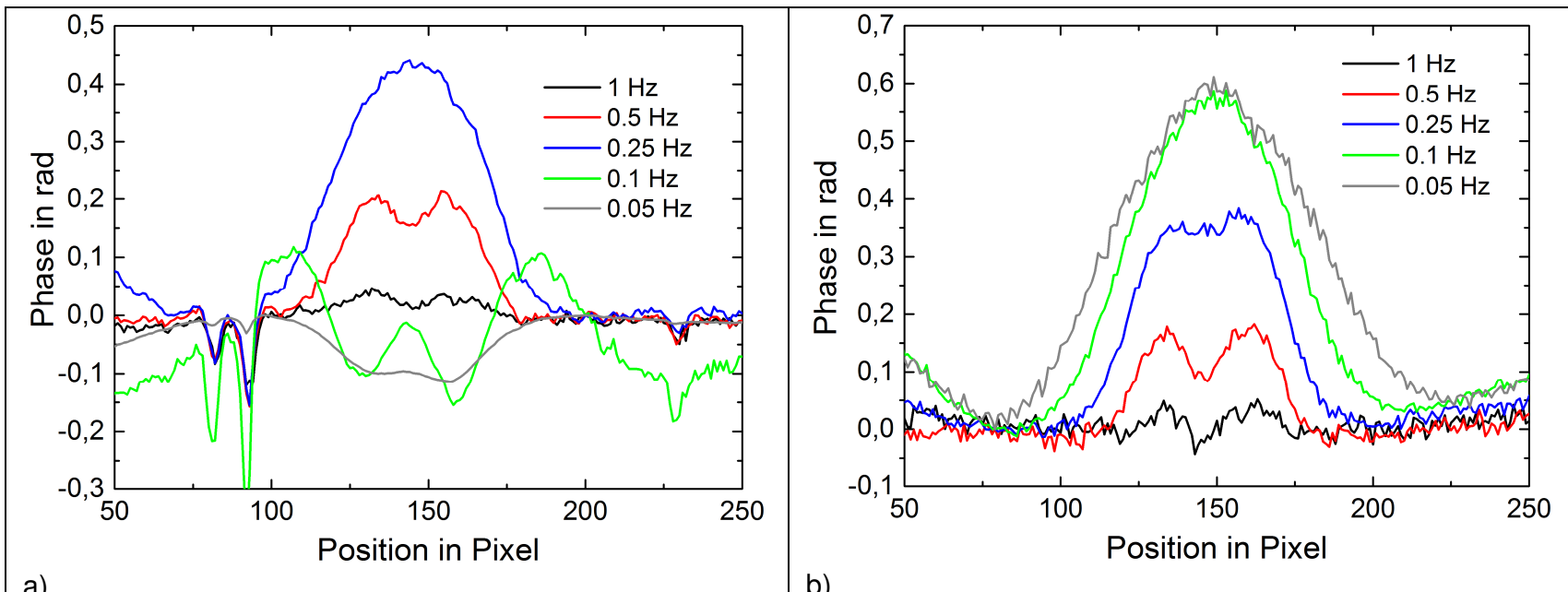

a)

Fig. 5: Line scans of all phase images recorded at the position of the red line in figure 4 of the steel sample with crossed notches. a) Line scans at different frequencies of the data recorded with lock-in excitation. b) Line scans at different frequencies of the data recorded with flash excitation.

\subsubsection{CFRP plate with flat bottom holes}

Also for the CFRP plate, phase images have been calculated by FFT for lock-in and flash excitation. These are shown in figure 6 for frequencies from $0.25 \mathrm{~Hz}$ down to $0.01 \mathrm{~Hz}$. Also the diffusion length for each frequency is shown calculated from a thermal effusivity of CFRP of $0.6 \times 10^{-6} \mathrm{~m}^{2} / \mathrm{s}$. It can be observed that with descreasing frequency, the signature of more and more flat bottom holes appear and for the lowest frequency of $0.01 \mathrm{~Hz}$, also the holes with the largest remaining wall thickness can be detected except for the holes with the smallest diameter of $4 \mathrm{~mm}$. Here, only the holes in the upper raw are visible. Especially for the larger holes, the appearing correlates with the diffusion length and the remaining wall thickness. For flash excitation, this appearance occurs at slightly higher frequencies than for lock-in excitation, which might be related to the broadband excitation. At first view, the spatial resolution of lock-in and flash excitation seems to be similar. Thus, for a more detailed analysis line scans along the three marked red lines have been extracted as shown in figure 7.

In figure 7 a) and b), the line scans of line 1 across three holes with a diameter of $32 \mathrm{~mm}$ and increasing remaining wall thickness from left to right are displayed. The phase contrasts of the holes for lock-in and flash excitation are more or less the same and the relations of the contrast of the holes to each other is changing similarly with excitation frequency. The SNR seems to be higher for the lock-in excitation. With lock-in, also the single fibre bundles could be resolved which was not possible for flash excitation.

The line scans of line 2 across three holes with a diameter of $16 \mathrm{~mm}$ and increasing remaining wall thickness similar to the hole of line 1 are depicted in figure $7 \mathrm{c}$ ) and d). Although the behaviour of the phase contrast is similar as for line 1, the values of the phase contrasts are slightly lower as those of the larger holes.

Figure $7 \mathrm{e}$ ) and f) show the line scans along line 3 for the holes with a diameter of $8 \mathrm{~mm}$ and less remaining wall thicknesses as for the larger holes. Here, the remaining wall thickness is decreasing from left to right. Again, the phase 
contrast for lock-in and flash excitation is similar. For the shallowest hole on the right with a remaining wall thickness of $0.15 \mathrm{~mm}$, a phase wrap could be observed for lock-in as well as for flash excitation. It seems that the widths of the hole signatures are slightly smaller for lock-in excitation than for flash excitation, thus the spatial resolution of lock-in excitation is a bit higher.

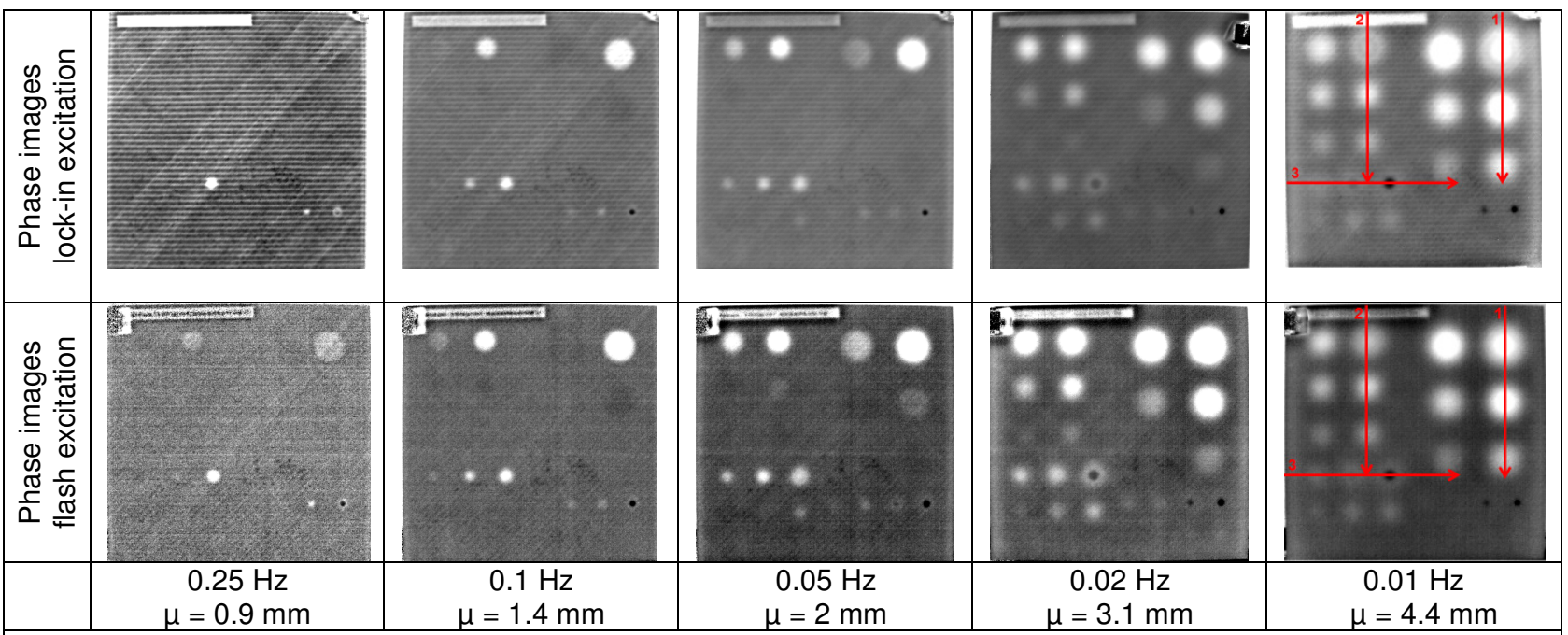

Fig. 6: Phase images of CFRP plate with flat bottom holes with different diameters and remaining wall thicknesses. Top: Phase images of lock-in measurements at different frequencies. Bottom: Phase images of flash thermography. The red lines 1 to 3 mark the positions of the line scans.
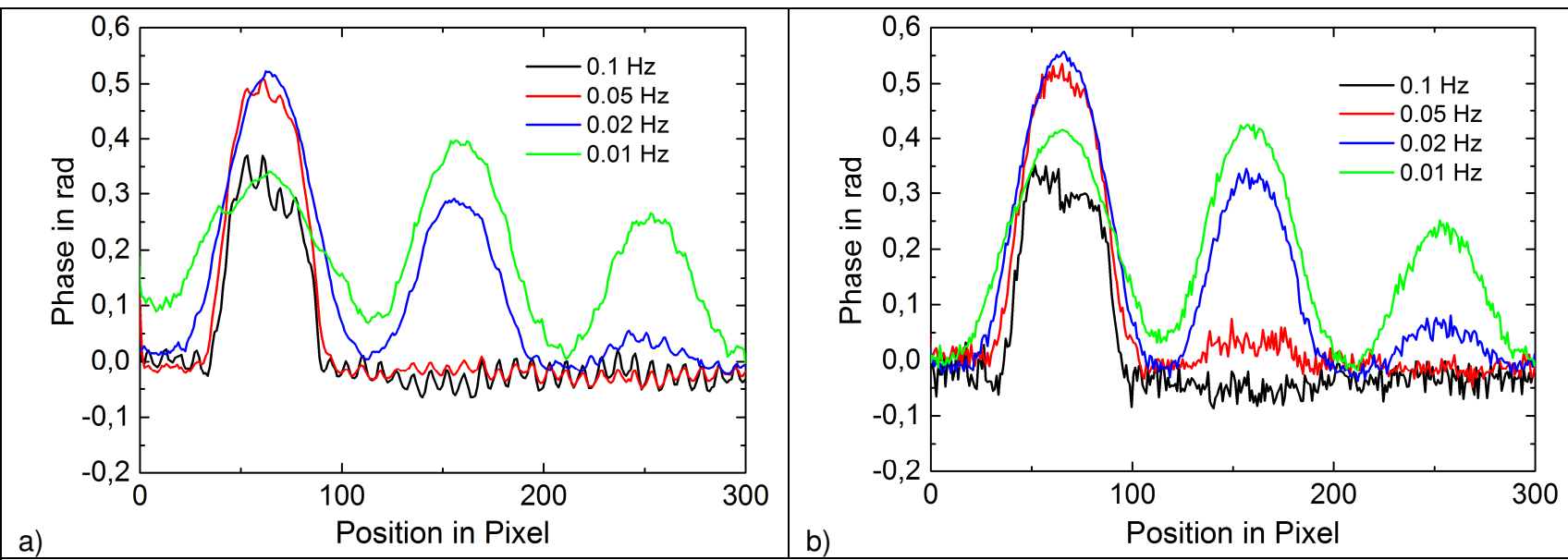

a)

Line 1, hole diameter $32 \mathrm{~mm}$, remaining thicknesses of

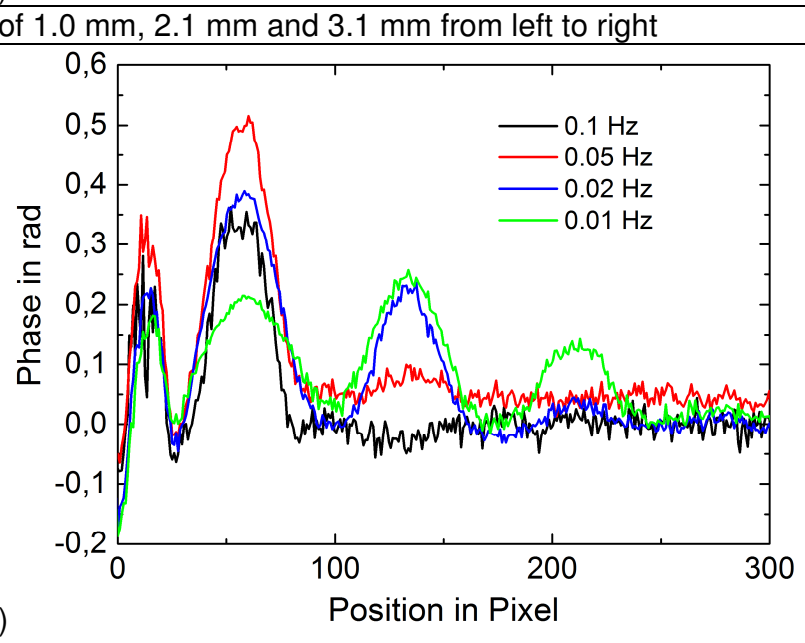

c)

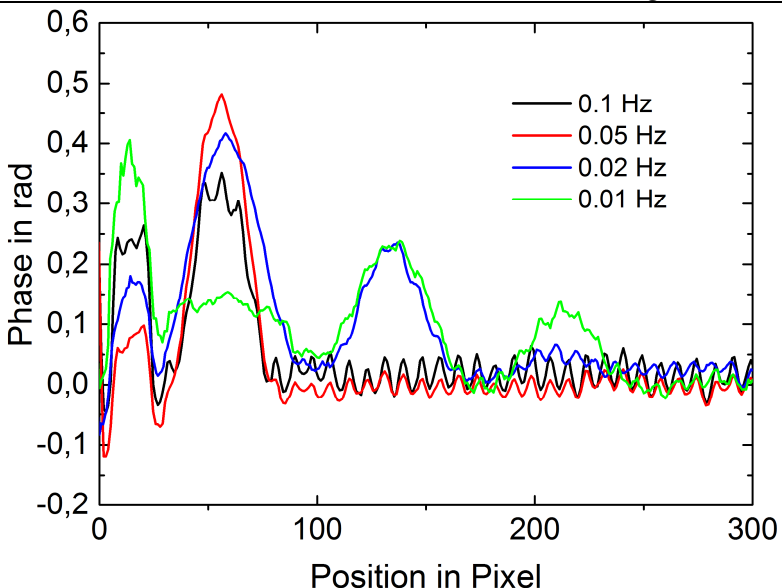

Line 2, hole diameter $16 \mathrm{~mm}$, remaining thicknesses of $0.9 \mathrm{~mm}, 1.6 \mathrm{~mm}$ and $2.7 \mathrm{~mm}$ from left to right 

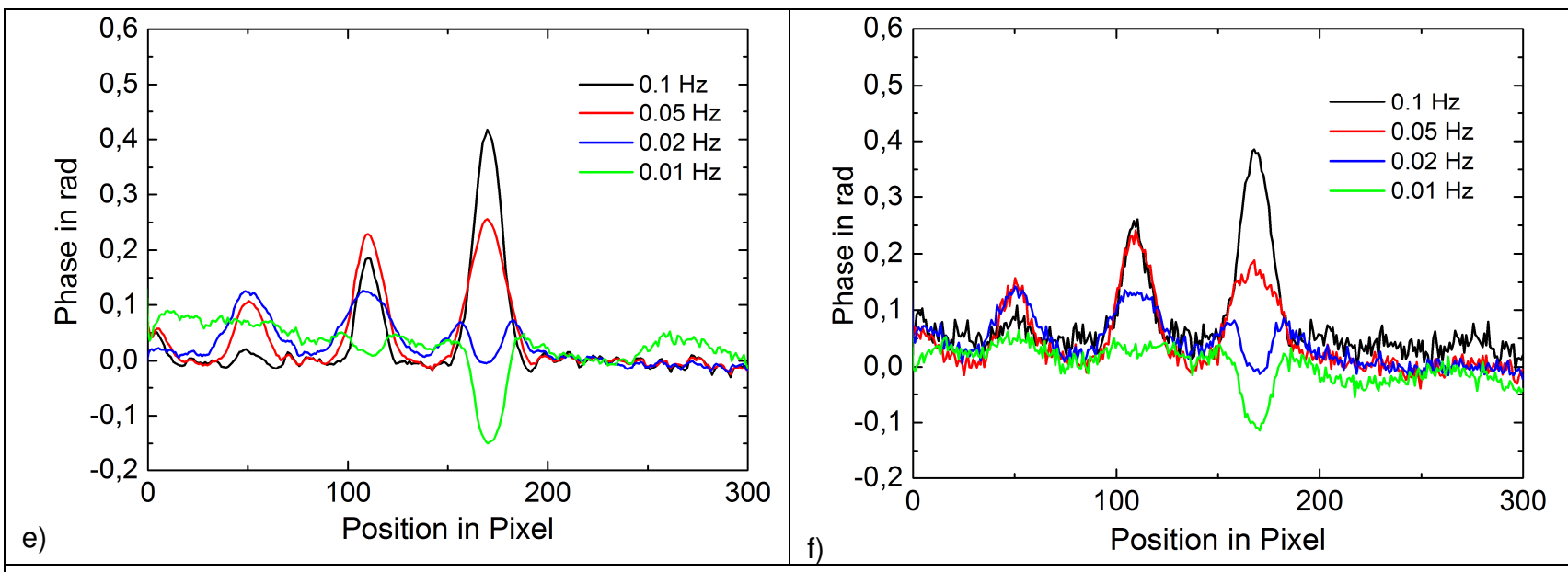

Line 3, hole diameter $8 \mathrm{~mm}$, remaining thicknesses of $1.25 \mathrm{~mm}, 0.7 \mathrm{~mm}$ and $0.15 \mathrm{~mm}$

Fig. 7: Line scans of all phase images recorded at the position of the red lines 1 to 3 in figure 6 of the CFRP sample with flat bottom holes. $a, c, e)$ Line scans at different frequencies of the data recorded with lock-in excitation. $b, d, f)$ Line scans at different frequencies of the data recorded with flash excitation.

In summary, from this comparison of lock-in and flash excitation it could be concluded that especially for materials with higher thermal diffusivity (metals) and structures at larger depths, lock-in excitation leads to much better spatial resolution of the signature of these structures. In all cases, it was found that the SNR of lock-in excitation and thus its sensitivity is higher than for flash excitation. But as the measurement duration required for flash excitation is much less than for lock-in excitation, flash excitation should be refereed for detecting shallow structures in metal or for investigating CFRP structures or further materials with low thermal diffusivity.

\section{Structure of a standard for the application of flash thermography}

Based on these systematic investigations, first an outline of a standard for flash thermography has been drafted as shown in table 2. This standardisation project is now handled within the DIN working committee NA 062-08-27 Visual and thermographic methods.

Table 2. Outline for a standard on the application of flash thermography

\begin{tabular}{|c|c|c|}
\hline Chapter & Titles & Remarks \\
\hline & Foreword & \\
\hline & Introduction & Principle of method \\
\hline 1 & Scope, area of application & $\begin{array}{l}\text { Detection of defects, quantification of defect coverage } \\
\text { and layer thickness, determination of thermal } \\
\text { properties }\end{array}$ \\
\hline 2 & Normative references & Thermography for NDT \\
\hline 3 & Terms and definitions & Flash thermography, PPT, PCA, SVD, TSR etc \\
\hline 4 & Personnel qualifications and duties & ISO 9712 \\
\hline 5 & Experimental set-up & \\
\hline 5.1 & Experimental configurations & Reflection and transmission \\
\hline 5.2 & Flash lamps & Flash duration, energy conversion, reflectors, filters etc \\
\hline 5.3 & $\begin{array}{l}\text { Further excitation sources with optical impulse } \\
\text { heating }\end{array}$ & LED, Laser, halogen lamps, arrays \\
\hline 5.4 & IR camera, requirements and set-up & $\begin{array}{l}\text { Including filters and lenses, specification of spatial, } \\
\text { thermal and temporal resolution and reproducibility }\end{array}$ \\
\hline 5.5 & Positioning of test objects & Off-line, in-line, on-site, automation \\
\hline 5.6 & Safety and protection of workers & EN 62471:2009-03 Photobiological safety of lamps and \\
\hline
\end{tabular}


http://dx.doi.org/10.21611/qirt.2014.032

\begin{tabular}{|c|c|c|}
\hline Chapter & Titles & Remarks \\
\hline & & lamp systems \\
\hline 6 & Selection and evaluation of parameters & \\
\hline 6.1 & $\begin{array}{l}\text { Reference test specimen and calibration } \\
\text { standards }\end{array}$ & $\begin{array}{l}\text { Type 1: Control of equipment } \\
\text { Type 2: Limits of method, artificial defects and } \\
\text { structures } \\
\text { Type 3: Real objects with real defects }\end{array}$ \\
\hline 6.2 & Penetration depth & $\begin{array}{l}\text { Dependence on thermal energy, thermal resolution of } \\
\text { IR camera, thermal properties of material }\end{array}$ \\
\hline 6.3 & Spatial resolution & Depth resolution, lateral resolution \\
\hline 6.4 & Detection sensitivity & $\begin{array}{l}\text { Aspect ratio, reflectivity, SNR, anisotropic thermal } \\
\text { material parameters }\end{array}$ \\
\hline 6.5 & Homogeneity of optical excitation & Array of flash lamps \\
\hline 7 & Preparation of test object & Blackening of the surface, no temperature gradients \\
\hline 8 & Testing procedure & Development of a test instruction \\
\hline 9 & Data analysis & $\begin{array}{l}\text { Defect detection, lateral position of defects, coverage } \\
\text { of defects, quantification of layer thickness, } \\
\text { determination of thermal diffusivity }\end{array}$ \\
\hline 9.1 & Temperature contrast & $\begin{array}{l}\text { Thermogram with early or maximum temperature } \\
\text { contrast, temporal development of temperature } \\
\text { contrast }\end{array}$ \\
\hline 9.2 & Pulse phase thermography (PPT) & $\begin{array}{l}\text { Influence of measurement duration and frame rate, } \\
\text { blind frequency for quantification of depth }\end{array}$ \\
\hline 9.3 & Thermal signal reconstruction (TSR) & Quantification of depth from maximum of $2^{\text {nd }}$ derivative \\
\hline 9.4 & Principal Component Analysis (PCA) & \\
\hline 10 & Test report & \\
\hline A1 & Template for test report & \\
\hline A2 & $\begin{array}{l}\text { Quantitative Measurement of radiated } \\
\text { energy of flash lamps }\end{array}$ & Development of an energy sensor \\
\hline A3 & Analytical 1D solution of heat conduction & \\
\hline A4 & Example of a test problem & \\
\hline
\end{tabular}

\section{Acknowledgements}

The presented results have been funded within two research projects titled Development of standards for active thermography with flash excitation (BMWi 01FS11002) and Development of standards for active thermography with lockin excitation (BMWi 01FS12011). These projects have been financed by the Federal Ministry for Economic Affairs and Energy of Germany within the research programme Transfer of research and development results through standardisation. The projects have been supported by DIN Deutsches Institut für Normung e. V. and DLR Deutsches Zentrum für Luft- und Raumfahrt. Sincere thanks are given to Martin Sengebusch from DIN for helpful discussions and assistance.

\section{REFERENCES}

[1] Ringermacher, H. I., Howard, D. R., Knight, B.: Thermal Imaging NDT at General Electric. In: Proc. of WCNDT 2012, http://www.ndt.net/article/wcndt2012/papers/359 wcndtfinal00359.pdf

[2] Ringermacher, H. I., Howard, D. R., Filkins, R. J.: Flash Quenching for High Resolution Thermal Depth Imaging. In: Review of Progress in Quantitative Nondestructive Evaluation 23, edited by D. O. Thompson and D. E. Chimenti, AIP Conference Proceedings vol. 700, American Institute of Physics,Melville, NY, 2004, pp. 477-481 
[3] Balageas, D.L.: Defense and illustration of time resolved pulsed thermography for NDE. QIRT Journal 9(1), 2012, pp. 3-32.

[4] Maierhofer, C., Röllig, M., Steinfurth, H., Ziegler, M., Kreutzbruck, M., Scheuerlein, C., Heck, S.: Nondestructive testing of Cu solder connections using active thermography. NDT \& E International, Volume 52, November 2012, Pages 103-111.

[5] Maierhofer, C., Röllig, M., Ehrig, K., Meinel, D., Céspedes-Gonzales, G.: Validation of flash thermography using computed tomography for characterizing inhomogeneities and defects in CFRP structures. Accepted for publication at Composites Part B, 2014

[6] Bennett, C.A.; Patty, R.R.: Thermal wave interferometry: A potential application of the photoacoustic effect. Appl. Opt. 21 (1982), pp. 49-54.

[7] Busse, G.; Wu, D.; Karpen, W.: Thermal wave imaging with phase sensitive modulated thermography. J. Appl. Phys. 718 (1992), pp. 3962-3965

[8] Röllig, M., Steinfurth, H., Ziegler, M.: Untersuchung von Hochleistungs-LEDs für den Einsatz in der zerstörungsfreien Prüfung mittels Thermografie. In: DGZfP-BB 143 (Vortrag 3) Thermographie-Kolloquium 2013, http://www.dgzfp.de/Portals/thermo2013/BB/vortrag\%203.pdf

[9] Holtmann, N., Artzt, K., Gleiter, A., Strunk, H. P., Busse, G.: Iterative improvement of lock-in-thermography results by temporal and spatial adaption of optical excitation. In: Proc. of QIRT 2012, http://www.qirt.org/archives/qirt2012/papers/QIRT-2012-348.pdf

[10] Montanini, R.: Quantitative determination of subsurface defects in a reference specimen made of Plexiglas by means of lock-in and pulse phase infrared thermography. Infrared Physics \& Technology 53 (2010) 363-371.

[11] Pickering, S., Almond, D.: Matched excitation energy comparison of the pulse and lock-in thermography NDE techniques. NDT\&E International 41 (2008) 501- 509. 